\title{
THE TYPES AND THE FUNCTIONS OF THE FILLERS USED IN BARACK OBAMA'S SPEECHES
}

\author{
Paulus Yanuar Kharismawan \\ Sanata Dharma University \\ yanuarkh@gmail.com
}

DOI: https://doi.org/10.24071/ijhs.2017.010112

received 9 November 2016; revised 21 March 2017; accepted 28 June 2017

\begin{abstract}
This study deals with the production of fillers used in Barack Obama's speeches. This study is to investigate the types and functions of fillers used by Barack Obama. The study seeks to answer two research questions: (1) what are the types of fillers in Barack Obama's speeches? and (2) What are the functions of fillers in Barack Obama's speeches? In order to answer these problems, the researcher applied Rose's (1998) theory on the types of fillers which combined with similar notions on the types and functions of fillers which taken from Stenström (1994) and Baalen (2001). This study adopted a descriptive qualitative approach which used a discourse analysis to conduct this study. This study aims to introduce the types and the functions of fillers and to increase the learners' awareness of fillers when they hesitate in the foreign language, which is actually the very nature of speaking.
\end{abstract}

Keywords: filler, types of fillers, functions of filler, Barack Obama

\section{Introduction}

Language is a tool to have interaction in daily conversation. Doing an interaction means that people should be able to communicate to others. The communication would be meaningful if they use language as the tool to communicate. Bickerton (1945) stated, "Language is a tool of communication while human intelligence is the result of the accelerated growth and unusual size of human brains" (p. 14). It means that communication and language are two components which cannot be separated from human being.

Learning to speak a second language (SL), especially foreign language (FL) is not simple as possible. It requires many efforts in understanding and applying the foreign language, commitment in learning, and developing the awareness as each language has its own rules (Santos, Alarcón, \& Pablo, 2016, p. 1). It is true when learning foreign language takes place in a context where the target language does not commonly use foreign language outside the foreign language classroom. According to Holmes (2013) and Chaika (2008), people need to develop not only the linguistic competence but also the appropriate communicative competence as well in communicating any foreign language. Therefore, understanding how to 
pronounce words correctly, use the appropriate grammar, and choose a proficient vocabulary does not guarantee the success to be able to speak a foreign language.

Since speaking foreign language is not easy, sometimes people make some pauses during speaking. In fact, many spontaneous speakers of various languages have pauses on their speaking which are taken when needed (Erten, 2014, p. 1). This phenomenon is commonly called filler. Fillers are a moment when someone pause their speaking to think what they want to say without give the impression if we finish our speaking. In daily conversation, people often use $u h, e r, u m, a h$, ehm, well, I mean, you know, or similar expressions. According to Baalen (2001), these kinds of utterances are called fillers. He also describes the fillers as sounds or words or phrases that could appear anywhere in the utterance and could be deleted from the utterance without a change in content. Clark and Tree (2002) claim that fillers serve a communication function, having a place in the speakers' vocabulary. Fillers are not the main message; they just help to have a meaning in sentences.

One of the ways of interactional communicating is by public speaking. Hasling (2006) defines public speaking as a type of communication in which a person has the attention of many people for some period times (p. 8). The examples of public speaking are speech, lecture, and presentation. In this study, the researcher investigates the speech as one of the types of public speaking.

In education field, filler is seen as a negative perception in speaking because it may decrease the fluency grade. Dlugan (2011) claims that filler words can weaken our credibility and can indicate that we are lack of preparation. He also concludes that fillers are bad in speaking. However, some experts explain that fillers have a positive perception. Fillers have types and functions. Fillers have various functions which depend on the situation of the speaker (Schiffrin, 1978, p. 154). Therefore this study aims to investigate and initiate the types and functions of fillers in order to raise awareness of avoiding fillers in speaking. Afterwards the researcher formulates two research problems: (1) what are the types of fillers used in Barack Obama's speeches? and (2) What are the functions of fillers used in Barack Obama's speeches?

\section{Theory}

Being a key concept, fillers are pause moments in speaking which the speaker produces some utterances or just silence. In this study, the researcher classifies the fillers into three types which are asilent pause filler, an unlexicalized filler, and a lexicalized filler. On the other hand, the researcher also describes the functions of fillers.

\section{The Definition of Filler}

According to Tottie (2011), the first researchers who studied on fillers, specifically on $U h$ and $U m$, were psycholinguists. She also mentioned the other researcher, such as Maclay \& Osgood (1959), Goldman-Eisler (1961), Stenström (1990), Kjellmer (2003), Gilquin (2008), who conducted on the topic of filler. Stenström (1994) defines the filler as lexically an empty item with uncertain discourse functions, except to fill a conversational gap (p. 222). It means that the fillers commonly occur to mark of hesitation or to hold control of a conversation while the speaker thinks what to say next. 


\section{The Types of Fillers}

According to Stenström (1994), fillers are categorized into two types; those are a silent pause and a filled pause (p. 1). On the other hand, Rose (1998) also divides the filled pauses into two types. The first one is an unlexicalized filled pauses and the second is a lexicalized filled pause.

Silent pauses are pauses that appear in strategic places of the sentences (Stenström, 1994, p. 7). According to Wu (2001), silent pauses define as the unfilled pauses when they occur in the middle of phrases and words (p. 3). As in Wu's definition, Matthei and Roeper (1983) also argue that silent pauses tend to occur within phrases of the sentence (p. 164). This statement is also supported by Brown and Yule (1983) that silent pauses are pauses which usually precede the utterance and help the speaker to plan putting the words into the utterances ( $p$. 129). They also define silent pauses as extended pauses because they usually extend between 3.2 to 16 seconds and cause the speakers to provide sufficient information to the hearers (p. 163). Therefore, silent pauses are pauses which are not filled with any sound or utterance.

Filled pause is a hesitation in spontaneous speech partly or wholly taken up by a speech sound like ah, err, uh, et cetera (Clark, 1977, p. 561). Similarly, in 1983, Brown and Yule defined filled pauses as pauses which usually appear in the form of sounds or words and in some places of the sentence (p. 129). Moreover, filled pauses are the gap between words and forward planning and thinking about what the speakers want to say (Carter, Goddard, Reah, Sanger, \& Bowring, 1997, p. 201). Based on those definitions about filled pauses, the researcher concludes that filled pauses are any utterances produced by a speaker when she plans to say something. Furthermore, Rose (1998) categorizes filled pauses into two types; those are an unlexicalized filled pause and a lexicalized filled pause (p. 7).

Unlexicalized filled pauses are non-lexemes (non-words) filled pauses which speakers use to indicate hesitation while the speaker think what to say next utterances (Rose, 1998; Baalen, 2001). In addition, Baalen (2001) also gives some examples of unlexicalized filled pauses, such as ehm, uh, err, ee, ah, um, and so on (para. 7). The definition of unlexicalized filled pauses is also supported by Juan (2006), he says that ehm, uh, err, ee, ah, um and other vocalizations which belong to unlexicalized filled pauses are the easiest sounds which made while having a speaking. Afterwards, he calls them as "neutral vowel sounds" (para. 1).

According to Rose (1998), claim that lexicalized filled pauses are fillers in the form of word or short phrases, such as like, well, yeah, sort of, you know, if you see what I mean, and so on (pp. 7-8). On the other hand, Baalen (2001) also states a similar statement that lexicalized filled pauses consist of the phrases you know and I mean which are mostly used when a speaker is grouping for words but does not want to give up the claim to the floor (para. 1). Furthermore, she suggests that one type of the fillers is like (when it is not used as verb or preposition) and well (not in the initial position). Stenström (1994) also notes that one type of fillers, which is similar to the lexicalized fillers, is verbal fillers, such as well, $I$ mean, and sort of.

Considering the types of fillers from Rose (1998) and Stenström (1994), the researcher summarized the types of fillers into three; they were a silent pause, an 
unlexicalized filled pause, and a lexicalized pause. In order to investigate the filler words, the researcher just used the unlexicalized filled pause and lexical filled pause in this study.

\section{The Functions of Fillers}

Actually, fillers have many functions. Fillers have various functions which depend on the situation of the speaker (Schiffrin, 1978, p. 154). In 2002, Clark and Fox Tree claimed that fillers served a communicative function and had a place in the speaker's vocabulary (p. 97). Nevertheless, they do not define as primary message in a communication. In other words, the use of a filler only helps the way of speaking, not the meaning in the communication. However, Corley and Stewart (2008) describe that deliberating fillers in the sense of communication function is not certain (p. 592). Therefore, fillers are used when the speaker is uncertain about his/her next utterance or he/she has choices to make in his utterance.

There are at least five functions of fillers that will be explained further. They are hesitating, empathizing, mitigating, editing term, and time-creating devices. The researcher analyzed the productions of fillers and defined the functions by considering the context of situation from the utterances. In order to answer the second research problem, the researcher used the functions of fillers based on Stenström (1994), Foss and Hakes (1978), Wu (2001), and Baalen (2001).

Fillers have the function as hesitation devices. Stenström (1994) defines a mark of hesitation as one of the functions of fillers. Foss and Hakes (1978) hesitations are pauses which increase in the places of a sentence when a speaker has difficult decision in using the words (p. 184). Matthei and Roeper (1983) and $\mathrm{Wu}$ (2001) clarify that these fillers occur when the speaker must stop and think about what he/she will say next and when he/she is putting a sentence together. Most of filled pauses (ee, em, err, uhm, ah, hm, et cetera) are used as the breathing pauses, such pauses generally match semantic-syntactic boundaries (Stenström, 1994, p. 7). Therefore, filled pauses are used for the hesitation purposes.

The speaker can use filler as an attention-getting device. It means that the speaker can check whether the listener pays attention or not. Based on Stenström (1994), fillers define as an invitation for the listener to be involved in what the speaker says (pp. 64-65). The examples of fillers as empathizing purposes are well, you know, right, hey and so on. They often appear at the beginning or at the end of a turn. Therefore, Jordan (2001) concludes that fillers can also be the indicators used by the listeners as a response in order to tell the speaker that the message is received, understood, or unclear, so the speaker knows that the listeners are giving response to what he/she says (p. 12).

Fillers can also serve as mitigating devices. Baalen (2001) assumes that fillers can mitigate utterances in order not to hurt the addressee's feelings (para. 6 ). She also highlights the fillers as a solidarity marker or politeness device. She explains that protecting face needs is an important function of fillers because face needs are the need to feel liked (positive face needs) and the need to have one's personal space respected (negative face needs). Fillers as like well, ehm, eer, and okay can be functioned as mitigating or politeness devices.

The editing term is also one of the filler functions. According to Baalen (2001), fillers are used to correct the speech errors in the utterances' speakers. In 
the other word, the speaker is aware if he/she makes a speech error. Then, he/she wants to correct it. I mean, um, ehm, uh, huh, ee, et cetera can indicate the speaker's awareness of the speech error followed by her/his attempt to correct it. In correcting the speech errors, the speakers replace certain old words with new ones, so it indicates that the old words have been misplanned. Sometimes, the speaker also repeats the speech error directly.

According to Stenström (1994), fillers can also be used as time-creating devices. Fillers give some time for the speaker to think about what to utter next. Stenström (1994) argues that the common form of fillers used as the time-creating devices is the lexical repetition (pp. 77-78). Moreover, lexical repetition consists of two types. The first is single words repetition. It means that the speaker repeats a single word in his/her turn. The second is clause partial repetition. It is the clause repetitions which appear in his/her turn. All repetitions in the utterances function as the fillers in order to give some time for the speaker to plan what to say next.

\section{Method}

Since the aim of this study was to investigate the types and functions of fillers used by Barrac Obama, this study was conducted by using descriptive qualitative approach. It was also reported in the form of description as Bogdan and Biklen (1982) suggested that the written word was very important in qualitative research to record data and disseminate the findings (p. 28).In this descriptive qualitative approach, the researcher conducted a discourse analysis. According to Wood and Kroger (2000), discourse analysis defines as a person's perception that contains of methodological and conceptual elements (p. 3). Furthermore, they also state that discourse data includes spoken and written texts. In the other hand, Stark and Trinidad (2007) add that discourse analysis concerns on the language use. Therefore, the researcher conducted a discourse analysis to study the types and the functions of fillers in the utterances of Barack Obama's speeches.

The object of this research was Barack Obama's speeches which were taken from YouTube. There were three videos which used in this study. The first entitles Indonesia's Example to the World. The second is President Obama on Early Childhood Education. The last is The President Delivers a Statement on the attacks in Paris. Since this research conducted a discourse analysis, the researcher used the videos' and the transcripts' of Barack Obama's speeches.

To begin the study, the researcher described what fillers are according to several experts. Then, the researcher looked for and chosen the videos which were used. After collecting the objects of this study, the researcher wrote the transcripts of the selected videos. In the next part of the research process, the videos and the transcripts were analyzed by using the theories already written in part 2 . In this process, the researcher used three steps. First, the researcher looked for some videos about Barack Obama's speeches, and then found the words or sentences containing fillers in his utterances. Second, the findings were analyzed and classified into the types of fillers. Third, the findings of classifications were defined and explained as the possible reasons why Barack Obama used those fillers in her speeches. Those three steps were to answer the research questions in 
this study. Finally, the researcher drew the conclusion based on the finding in this research.

\section{Findings and Discussion}

This part discusses the results of this study. It consists of two sections, namely the types of fillers and the functions of fillers occurrence in the utterances used in Barack Obama's speeches.

\section{The Types of Fillers}

There are two types of fillers; those are a silent pause and a filled pause. Since this study was to investigate the word fillers, the researcher just focused on the filled pause. This study classified the types of filled pauses based on Rose's theory. According to Rose (1998), there are two types of filled pause; those are an unlexicalized filled pause and a lexicalized filled pause.

According to Rose (1998) and Baalen (2001), unlexicalized filled pauses mean non-lexemes (non-words) filled pauses which speakers use to indicate hesitation while the speaker think what to say next utterances. Here were some examples to represent the data:

- BO: eeu Pulang kampung nih. (Applause.)

- BO: The kids we saw today that I had a chance to spend time with in Mary's classroom; um they're some of the lucky ones...

In those two examples, there were eeu and um which classified as unlexicalized filled pauses. It was because those two utterances was not a word and did not have meaning.

Based on Rose (1998), lexicalized filled pauses are fillers in the form of word or short phrases. Here were some examples of lexicalized filled pauses:

- BO: I still remember the call of the vendors. Satay! Right?

- BO: I mean, some of the younger teachers who are here, ...

- BO: ... I don't want to speculate okay.

There were right, I mean, and okay which appeared in Obama's speeches. Right and okay were in the form of word and I mean was in the form of phrases. Those three examples also had the meaning but they were still considered as lexicalized filled pauses because those words were not important as a part of their sentence. Therefore, whether those words were in the sentence or not, they could not change the meaning of the sentence.

\section{The Functions of Fillers}

Actually, fillers had many functions. Schiffrin (1978) argues that fillers have various functions which depend on the situation of the speaker (p. 154). There were at least five functions of fillers which became the focus on this study. They were hesitating, empathizing, mitigating, editing term, and time-creating devices. The researcher analyzed the productions of fillers and defined the functions by considering the context of situation from the utterances.

Stenström (1994) defines a mark of hesitation as one of the functions of fillers. He also give some examples of fillers as a mark of hesitation, such as ee, em, err, uhm, ah, hm, et cetera. In this study, fillers as hesitation devices appeared the most in the selected videos. These were some example of fillers as hesitation devices: 
- BO: Most of them gave way to unpaved roads and $\boldsymbol{e} \boldsymbol{e}$ the kampongs.

- BO: ... they're well-equipped as citizens with the $\boldsymbol{e} \boldsymbol{e} \boldsymbol{e}$ critical thinking skills that they need ...

- BO: $\boldsymbol{e m}$ We don't yet know all the details of what has happened.

Based on the situation, ee, e e e, and em were said by adding a slight pause. It meant that those fillers appeared to give the speaker time to think about what he/she would say next.

Based on Stenström (1994), fillers define as an invitation for the listener to be involved in what the speaker says (pp. 64-65). Here were same sample of those fillers:

- BO: ... (applause) hey, some folks from Menteng Dalam right here.

- BO: And what's more, I don't think you'll find a working parent in America who wouldn't appreciate the peace of mind that their child is in a safe, high-quality learning environment every single day. You know.

- BO: This is not babysitting. Right?

Based on the first example, Barack Obama wanted to invite the listeners to pay attention to him, so he said hey loudly. Then, you know and right indicated that whether the message was received and understood or not. According to those three examples, the researcher concluded that fillers as empathizing purpose usually appeared at the beginning or at the end of a sentence.

Baalen (2001) highlights fillers as a solidarity marker or politeness device. It meant that fillers were used to make the speech more polite. Here was an example of fillers as mitigating purposes:

- BO: ... we intend to be there with them in that same fashion $\boldsymbol{u h m}$.

In this situation, Barack Obama said the utterance of $u \mathrm{hm}$ by nodding his head. It meant that Barack Obama showed his respect.

According to Baalen (2001), fillers are used to correct the speech errors in the utterances' speakers. I mean, um, ehm, uh, huh, ee, et cetera can indicate the speaker's awareness of the speech error followed by her/his attempt to correct it. Sometimes, the speaker also repeats the speech error directly. Here were some examples to represent the data:

- BO: Lot of people keep keeping flowers around.

- BO: I mean, some of the younger teachers who are here, ...

In the first example, Barack Obama corrected his speech error directly. On the other hand, I mean referred to his previous sentence. By using I mean, Barack Obama would clarify his speech.

According to Stenström (1994), fillers can also be used as time-creating devices. He argues that the common form of fillers used as the time-creating devices is the lexical repetition. Fillers as time-creating devices meant that fillers give some time for the speaker to think about what to utter next. Here were some the examples of those filler:

- BO: ... that our children are are are are just sponges soaking stuff in

- BO: And as a young boy I was -- as a young boy I was coming to a different world. 
The first examples indicated single words repetition. It meant that Barack Obma repeated a word (are) four times. The second example referred to clause partial repetition where Barack Obama repeated a clause (as a young boy I was). However, those two kinds of repetition were to get some times to think what to say next. Fillers as time-creating devices were almost same with fillers as hesitating purpose. The different was fillers as hesitating purpose referred to unlexicalized filled pauses and time-creating devices referred to lexical filled pauses.

\section{Conclusion}

The results of this study showed that there were two types of fillers; those were unlexicalized filled pause and lexical filled pause. Furthermore, this study also showed five functions of fillers, namely hesitating, empathizing, mitigating, editing term, and time-creating devices. Based on those findings, the researcher concludes that fillers are not always considered as distraction of speaking. As the learners of foreign language (FL), we should know the fillers not only as a distraction of speaking but also as the way to improve our interaction.

The aims of this study are to introduce the types and the functions of fillers and to increase the learners' awareness of fillers when they hesitate in the foreign language, which is actually the very nature of speaking. Furthermore, the FL learners can learn and use fillers which are good to use. It is also help the FL learners to choose fillers which can bother our interaction. Therefore, this study has revealed that how important the fillers are in the interaction, especially in speech. In addition, to a certain extent, the findings of this study will also be expected to provide contributions for the development of the theory, especially to sociolinguistics study since this study is based on sociolinguistics.

\section{References}

Baalen, I. V. (2001). Male and female language: Growing together?. Retrieved from http://www.let.leidenuniv.nl/hsl_shl/van\%20Baalen.htm

Bickerton, D. (1995). Language and human behavior. Washington: University of Washington Press.

Bogdan, R. C. \& Biklen, S. K. (1982). Qualitative research for education: An introduction to theory and methods. Boston: Allyn and Bacon, Inc.

Brown, G. \& Yule, G. (1983). Discourse Analysis. London: Cambridge University Press.

Carter, R., Goddard, A., Reah, D., Sanger, K. \& Bowring, M. (1997). Working with texts: A core book for language analysis. London: Routhledge.

Chaika, E. (2008). Language the social mirror. (4 ${ }^{\text {th }}$ ed.). Boston: Heinle.

Clarck, H. H. \& Clarck, V. (1977). Psychology and language: An introduction to sociolinguistics. New York: Harcourt Brace Javanovich Inc.

Clark, H. H. \& Fox Tree, J. E. (2002). Using uh and um in spontaneous speaking. Cognition, 84, 73-111.

Corley, M. \& Stewart, O. W. (2008). Hesitation disfluencies in spontaneous speech: The meaning of um. Language and Linguistics Compass, 2(4), 589-602. 
Dlugan, A. (2011, December 4). How to stop saying um, uh, and other filler words. Retrieved on September 12, 2016, from http://sixminutes. dlugan.com/stop-um-uh-filler-words/

Erten, S. (2014). Teaching fillers and students' filler usage: A study conducted at ESOGU preparation school. International Journal of Teaching and Education, 2(3), 67-79.

Foss, D. J. \& Hakes, D. T. (1978). Psycholinguistics: An introduction to the psychology of language. New Jersey: Prentice-Hall, Inc.

Hasling, J. (2006). The audience, the message, the speaker $\left(7^{\text {th }}\right.$ ed.). Boston: Mc Graw-Hill.

Holmes, J. (2013). An introduction to sociolinguistics (4 ${ }^{\text {th }}$ ed.). New York: Routledge.

Hudson, R. A. (1980). Sociolinguistics ( $1^{\text {st }}$ ed.). London: Cambridge University Press.

Jordan, D. J. (2001). Leadership in leisure service: Making a difference $\left(2^{\text {nd }}\right.$ ed.). State College, PA: Venture Publishing, Inc.

Matthei, E. \& Roeper, T. (1983). Understanding and producing speech. New York: Universe Books.

Rose, R. L. (1998). The communicative value of filled pauses in spontaneous speech (Thesis). Brimingham: Brimingham University. Retrieved on October 6, 2016, from http://filledpause.com/biblio/rose-1998

Santos, N. M. B., Alarcón, M. M. H. \& Pablo, I. M. (2016). Fillers and the development of oral strategic competence in foreign language learning. Porta Linguarum, 191-201.

Schiffrin, D. (1978). Discourse makers. Cambridge: Cambridge University Press.

Starks, H. \& Trinidad, S. B. (2007). Choose your method: A comparison of phenomenology, discourse analysis, and grounded theory. Qualitative Health Research, 17(10), 1372-1380.

Stenström, A. (1994). An Introduction to Spoken Interaction. London: Longman.

The White House. (2010, November 9). Indonesia's example to the world. Retrieved from https://www.youtube.com/watch?v=niDPBTbJqS0

The White House. (2013, February 14). President Obama on early childhood education. Retrieved from https://www.youtube.com/watch?v=ZQco0S $\mathrm{cAJRg}$

The White House. (2015, November 13). The President delivers a statement on the attacks in Paris. Retrieved from https:/www.youtube.com/watch?v= 4qYeXxGnSIA

Tottie, G. (2011). Uh and $U m$ as sociolinguistic markers in British English. International Journal of Corpus Linguistics, 16(2), 173-197.

Wood, L. A. \& Kroger, R. O. (2000). Doing discourse analysis. Thousand Oaks, CA: Sage Publications.

Wu, J. (2001). A quantitative comparison of disfluencies types between native and non-native English speaker in spontaneous speech. Retrieved on October 10, 2016, from http://www.swarthmore.edu/SocSci/Linguistics/papers/ 2002/JeffWu.pdf 